\title{
STUDY ON THE APPLICATION OF CLEANING MODELS WITH HIGH SPEED WATER JETS TO CIP-PROCESSES
}

\author{
Hannes Köhler, Hannes Stoye, Thomas Weyrauch, André Boye, Marc Mauermann, Jens-Peter Majschak
}

Original scientific paper To meet consumer safety and high product quality there is a need of reliable cleaning processes in the food industry. To keep competitive position it is necessary to control costs of those cleaning in place (CIP) processes e.g. expenses for fresh and waste water, detergents and to minimize downtime of the production facilities. The removal of food soils with water droplet sprays are very little researched, especially the mathematical modelling. In this paper we show that the high pressure model of Leu et al. can be applied to low pressure spray cleaning of a food soil with marginal adaptations. We used an existing analytical model for the relation of cleaned width as a function of the standoff distance and considered the different structure of the water spray as well as a food specific cleaning behaviour. We validated the analytical model with experimental results by varying the equivalent nozzle diameter.

Keywords: CIP; cleaning model; spray; water jet

Analiza primjene modela za čišćenje s mlazovima vode na CIP postupke

Izvorni znanstveni članak Zbog sigurnosti potrošača i osiguranja visoke kvalitete proizvoda nužno je provesti pouzdane postupke čišćenja u prehrambenoj industriji. Za održavanje konkurentnog položaja potrebno je kontrolirati troškove tih cleaning in place (CIP) postupaka, na primjer troškove za slatku i otpadnu vodu, deterđente, i svesti na minimum vrijeme prekida rada proizvodnih pogona. Čišćenje mrlja od hrane raspršivanjem vode veoma je slabo istraženo, naročito matematički prikaz postupka. U ovom radu pokazujemo da se model visokog tlaka autora Leu et al. može, uz neznatne adaptacije, primijeniti na čišćenje mrlja raspršivanjem vode niskog tlaka. Primijenili smo postojeći analitički model za relaciju čišćene širine kao funkcije standoff udaljenosti i razmotrili različitu strukturu raspršene vode kao i specifično ponašanje mrlje pri čišćenju. Potvrdili smo analitički model eksperimentalnim rezultatima mijenjanjem promjera mlaznice.

Ključne riječi: CIP; model za čišćenjel; raspršivanje; vodeni mlaz

\section{Introduction}

The production of high-quality and hygienic products is given first priority in the food processing industry and is required by law (e.g. Machinery Directive 2006/42/EC). Cleaning in place (CIP) processes enable an automated cleaning of the manufacturing line without dismantling parts. However, contamination in processing machinery as well as cross-contamination after product changes still pose serious problems from an economic and technical perspective, usually with insufficient cleaning accounting for it. To guarantee high food quality regular and effective cleaning of food processing machines is essential. Consensus can be stated about the general factors of influence. In [1] the author describes the factors as a system dependent on i) kind of soil, ii) the machine design as well as iii) time, iv) chemistry, v) mechanics and vi) temperature as variables of the cleaning solution.

Although spray or jet cleaning is common standard in the food processing industry only few research efforts in the area of analysing cleaning performance have been reported $[2 \div 5]$. Most of the available investigations for removal by water jets are related to high-pressure topics. The use of high-pressure water jets ranges from cutting or erosion of material to cleaning purposes. Those applications are nowadays well established but nevertheless subject of current research $[6 \div 8]$. A few publications show similarities between high and low pressure cleaning like the existence of an optimal nozzle distance with maximum cleaning performance [2, 3]. However there are basic differences like the pressure range ( $\leq 10$ bar vs. $\geq 1000$ bar) and the kind of removed material. In comparison to the hard and brittle materials often with time independent mechanic character in high- pressure applications, the soft food soils are mainly time dependent [9]. In summary, no conclusion on the application and optimisation of low pressure spray cleaning systems in food processing machinery can be derived from the literature. Of special interest would be a model that relates the different operating parameters of the cleaning system and some kind of area cleaning performance. By means of such a model the efficiency of cleaning process could be estimated already in the design process or appropriate nozzles could be chosen with less effort. By Leu et al. [10] and Meng et al. [11] an analytical model was presented to describe the removal of coatings or deposits with high pressure water jets, suggesting an investigation of transferring this existing model to low pressure cleaning.

The basic approach of the cleaning model by Leu et al. is that the removal of oil and epoxy-based paint occurs due to fatigue failure of the soil caused by impinging water droplets. Their condition for removal is specified in Eq. (1), where $j$ is a mass flux $\left(\mathrm{kg} \cdot \mathrm{s}^{-1} \cdot \mathrm{m}^{-2}\right)$ and $S$ is the endurance limit of the soil. Here, the mass flux describes the spatial distribution of the mass flow rate of the cleaning liquid within the spray and is related to an infinitesimal cross sectional area.

$\lambda j \psi \geq S,[10]$

The factor $\psi$ is the speed of sound in water, resulting out of the theory of the water hammer effect. According to Leu et al. the stress coefficient $\lambda$ comprises effects of droplet size, thickness of soil and further properties of the substrate, soil and water. In case of an experiment with unvarying substances these parameters could be regarded 
as constant as well as the soil endurance limit. The analysis of Leu et al. is based on a rotationally symmetric water distribution within the jet. Due to the high pressure, the resulting high flow velocities, inner turbulence and the interaction with the surrounding air, the jet does not remain coherent (jet diameter $\approx$ nozzle diameter) but rather spreads linearly with increasing distance $l$ from the nozzle. In Eq. (2) $C$ is the spreading coefficient to determine the outer limit of the jet.

$R=C l$.

Additionally the radial coordinate could be nondimensionalized according to Eq. (3).

$\xi=\frac{r}{R}$

Further on they described the radial mass flux distribution by Eq. (4), where $j_{\mathrm{m}}$ is the mass flux at the center line.

$\frac{j}{j_{m}}=\left(1-\xi^{1,5}\right)^{3}$

By applying the law of conservation of mass the decreasing mass flux by increasing distance at the center line of the spray $j_{\mathrm{m}}$ could be determined out of the total mass flow rate per nozzle cross sectional area $j_{0}$.

$j_{0} \frac{\pi}{4} D^{2}=2 \pi \int_{0}^{R} j r \mathrm{~d} r=2 \pi j_{m} \int_{0}^{R} \frac{j}{j_{m}} r \mathrm{~d} r$.

The following Eq. (6) describes the dependency of $j_{0}$ on the operating parameters nozzle diameter $D$ and gauge pressure $p$, where $Q$ is the total volume flow rate and $\rho$ the density of water.

$j_{0}=\frac{\rho \cdot Q}{\frac{\pi}{4} D^{2}}=k \sqrt{2 p \rho}$.

The coefficient $k$ describes the flow resistance and could be calculated for each nozzle by the ratio of the real volume flow rate $Q$ to the theoretical volume flow rate given by Eq. (7).

$k=\frac{Q_{\text {real }}}{Q_{\text {theoretical }}}=\frac{Q}{\frac{\pi}{4} D^{2} \sqrt{\frac{2 p}{\rho}}}$. jets.

Combining Eq. (2) to (7) results in Eq. (8) for round

$j_{m_{-} \text {Leu }}=1,99 \cdot k \sqrt{p \rho} \cdot \frac{D^{2}}{C^{2} l^{2}}$.

Therewith the local mass flux within the jet is defined in all spatial dimensions. A critical standoff distance $l_{\mathrm{c}}$ could be determined, where the mass flux in the centre of jet (which is the maximum for every cross section) is equal to the critical mass flux necessary for removal, Eq. (1) becomes then Eq. (9).

$\lambda j_{m} \psi=S$.

To relate the critical standoff distance $l_{c}$ to the operating parameters nozzle diameter $D$ and gauge pressure $p$ Leu et al. derived the following Eq. (10), where $\lambda$ and $S$ are unknown but regarded as constant.

$l_{c_{-} \text {Leu }}=2,82 \cdot\left(\frac{\lambda \psi k}{S}\right)^{0,5} \cdot\left(\frac{D}{2 C}\right) \cdot(p \rho)^{0,25}$.

At the border between the cleaned and uncleaned area the condition $\lambda j \psi=S$ is valid for any cross section where

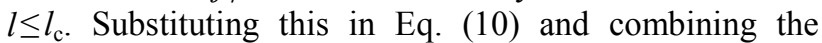
result with Eq. (8) yields Eq. (11)

$\frac{j}{j_{m}}=\frac{l^{2}}{l_{c}^{2}}$.

Finally Eq. (12) could be obtained with the aid of Eq. (2) to (4) and (11) to describe the cleaned width $w_{\mathrm{c}}=2 r$ of a water jet as a function of the critical distance and the jet spreading coefficient.

$w_{c}=2 C l\left[1-\left(\frac{l}{l_{c}}\right)^{\frac{2}{3}}\right]^{\frac{2}{3}}$.

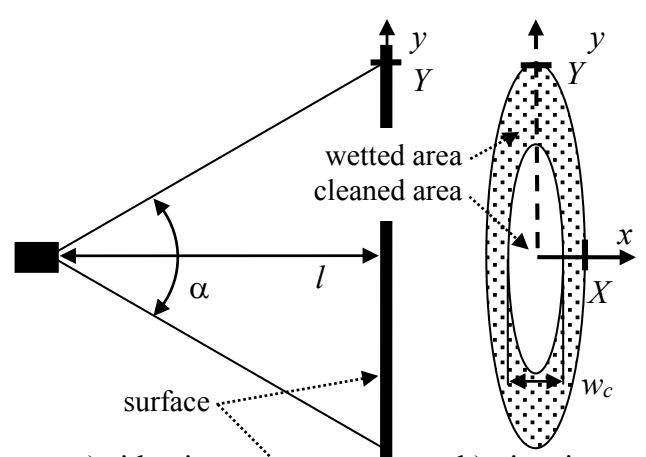

b) view in

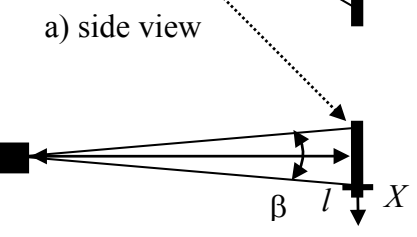

flow direction

c) top view

$x$

Figure 1 Schematic flat fan spray. Bold and dashed lines in b) correspond to Fig. 2

In the following we applied this approach to a flat fan nozzle. The spatial water distribution is not rotationally symmetric but could be described in a similar way in two dimensional form. The characteristic dimensions of a flat fan nozzle are shown in Fig. 1. 


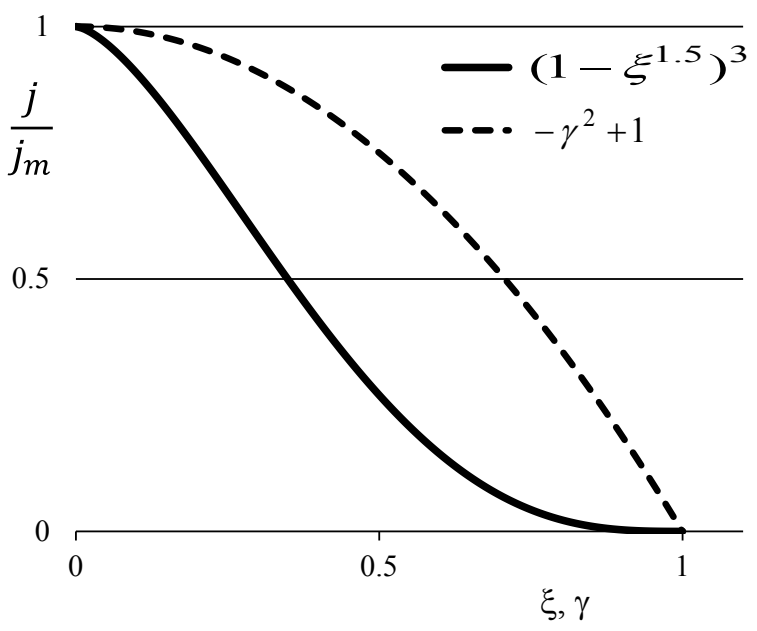

Figure 2 Normalized mass flux distribution in $\xi(x)$ and $\gamma(y)$ direction

Accordingly to Leu et al. we define in Eq. (13) and (14) the distance dependency of the jet limits and their dimensionless coordinates.

$X=\tan \left(\frac{\beta}{2}\right) \cdot l=C l$.

$Y=\tan \left(\frac{\alpha}{2}\right) \cdot l$.

$\xi=\frac{x}{X}$

$\gamma=\frac{y}{Y}$

In $y$ direction the used flat fan nozzles have a parabolic water distribution Eq. (15), as given by the manufactures data sheet [13], and in $x$ direction we assume the same water distribution as Leu et al. in Eq. (4). We will later show that the later assumption is in good agreement with the results. Fig. 2 shows these normalized distributions.

$\frac{j}{j_{m}}=-\gamma^{2}+1$

The law of conservation of mass is now for the two dimensional case as in Eq. (16). The factor 4 is due to the fact that the double integral is regarded as a quarter of the jet.

$j_{0} \frac{\pi}{4} D^{2}=4 \int_{0}^{X} \int_{0}^{Y} j \mathrm{~d} x \mathrm{~d} y=$

$=4 j_{m} \int_{0}^{X}\left(1-\xi^{1,5}\right)^{3} \mathrm{~d} x \int_{0}^{Y}\left(-\gamma^{2}+1\right) \mathrm{d} y=$

$=4 j_{m} X Y \int_{0}^{1}\left(1-\xi^{1,5}\right)^{3} \mathrm{~d} \xi \int_{0}^{1}\left(-\gamma^{2}+1\right) \mathrm{d} \gamma$

By applying the same analytic steps as Leu et al. to the flat fan spray the critical standoff distance results in Eq. (17).

$$
l_{c}=2,127 \cdot\left(\frac{\lambda \psi k}{S \cdot \tan \frac{\alpha}{2} \cdot C}\right)^{0,5} \cdot\left(\frac{D}{2}\right) \cdot(p \rho)^{0,25} .
$$

Furthermore the equation for the cleaned width in $x$ direction of a flat fan is in this case exactly the same as Eq. (12). This results from the fact that the same mass flux distribution in $r$ and $x$ direction was applied and Eq. (12) is independent from the mass flow distribution in $y$ direction. The dependency of $w_{\mathrm{c}}$ on $l$ in $y$ direction could be obtained in the same way by Eq. (11) and (15) leading to Eq. (18).

$$
w_{c-y}=2 \cdot \tan \left(\frac{\alpha}{2}\right) \cdot l \cdot\left[1-\left(\frac{l}{l_{c}}\right)^{2}\right]^{0,5} .
$$

\section{Experimental techniques}

The food model soil is vanilla flavoured blancmange from the local supermarket. Stainless steel sheets $(500 \times 500 \times 1 \mathrm{~mm}$, AISI 304 2B finish $)$ were precleaned with water, acetone and ethanol before soiling. The blancmange is homogenized and heated up to $25^{\circ} \mathrm{C}$ and then applied on homogeneously. Afterwards the sheets dried at room temperature for $24 \mathrm{~h}$. The soil mass per area $m_{0}$ was determined by differential weighing.

For cleaning experiments the test rig shown in Fig. 3 was used. An upright standing metal sheet is cleaned for 10 min continuously by a flat fan nozzle (Lechler $\mathrm{GmbH}$, Type 660 [13]). The cleaning progress is captured online by a camera (Nikon D200). During cleaning the soil is illuminated by two UV lamps. The inherent fluorescence properties of the blancmange result in a high contrast between cleaned and soiled areas. To maintain the light conditions constant during the cleaning process the test set up is surrounded by a black box to shield from extraneous light. The experiment is controlled by a computer, which regulates the pump pressure, opens the valve, triggers the camera and records sensor data.

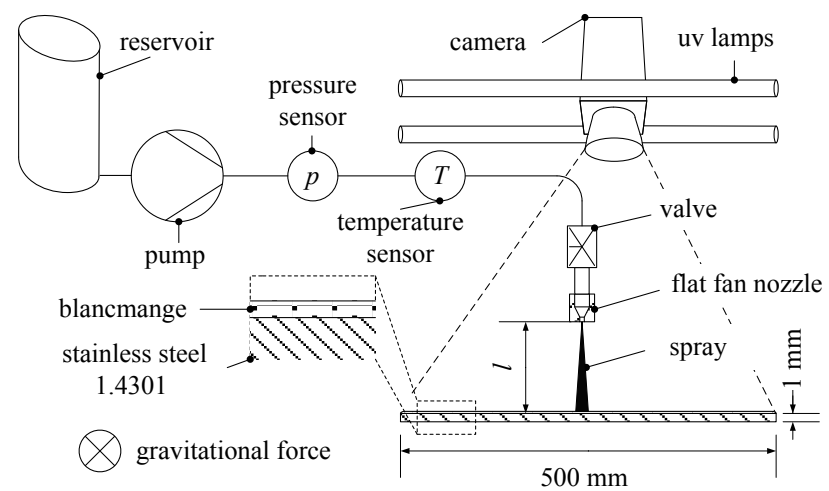

Figure 3 Cleaning test rig with online monitoring system (top view)

Before the valve opens a first photo of the test sheet is captured under dry conditions. All acquired images of an experiment were automatically analysed by a MATLAB ${ }^{\circledR}$ script. The images were converted into grey values and cropped to a region of interest (ROI) with the 
boundaries of the test sheet. Afterwards the test sheet area was divided into subsections of $5 \times 5 \mathrm{~mm}^{2}$. The mean grey value of each subsection is calculated and standardized to the initial dry grey value. Previous studies revealed that the normalized grey value corresponds to the amount of soil [12]. By means of a threshold a subsection is regarded as clean (normalized grey value $<0,5$ ) or soiled (normalized grey value $\geq 0,5$ ). For the experiments presented here the cleaned width $w_{\mathrm{c}}$ is determined in $x$ direction by considering the horizontal subsections in the vertical center of the spray as illustrated in Fig. 4 (squares within the dashed rectangle). Larger nozzle distances and the high spray angle $\alpha$ of $90^{\circ}$ lead the spray to exceed the sheet in $y$ direction. Therefore the validity of the assumed mass flux distribution in $y$ direction could not be checked. Nevertheless the analysis of the cleaned width in $x$ direction remains unaffected. The cleaned width is finally obtained by dividing the cleaned area by the subsection height. In this work the cleaned width is evaluated at discrete points in time $t=\{30,60,120\} \mathrm{s}$ for further analysis.

A series of experiments was conducted according to Tab. 1 with different nozzle diameters and distances. In all cases the gauge pressure has been 2 bar and the cleaning fluid purified water with a temperature of $22,5 \pm 1,5^{\circ} \mathrm{C}$. The coefficient $k$ is calculated for each nozzle by the ratio of the volume flow rate $Q$ given in the manufacturers data sheet to the theoretical volume flow rate given by Eq. (7).

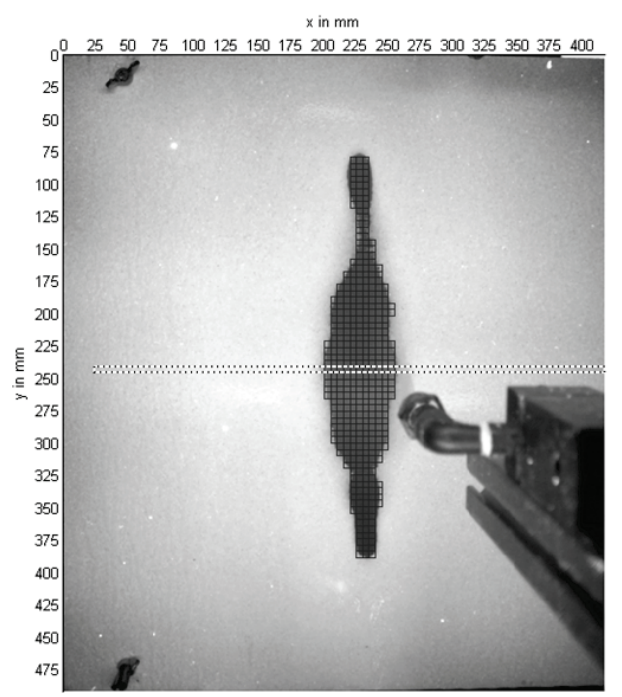

Figure 4 Sample picture from data processing to determine the cleaned width. Nozzle B, $D=1 \mathrm{~mm}, p=2$ bar, $l=200 \mathrm{~mm}, t=120 \mathrm{~s}$.

To relate the experimental series among themselves for a certain point in time the following factors were regarded as constant: i) the unknown endurance limit of the soil $S$, ii) the speed of sound in water $\psi$, iii) the spray angle $\alpha$, iv) the gauge pressure $p$ and v) the density of water $\rho$. In contrast to Leu et al. we did not assume $\lambda$ and $k$ as constants, as shown in Tab. 1 , where differences in $k$ and $m_{0}$ are evident. Since the stress coefficient is related to soil thickness and assuming that the soil thickness is homogeneous over the sheet, $\lambda$ is regarded as proportional to $m_{0}{ }^{-1}$.

Considering Eq. (1) means that a thicker soil layer requires a higher mass flow rate for removal. This assumption leads to Eq. (19), where the dimensionless factor $\lambda$ is related to $m_{0}^{-1}$ by introducing an unknown, but constant, factor $\lambda^{*}$.

$$
\lambda=\frac{\lambda^{*}}{m_{0}}
$$

In Eq. (17) $\lambda$ is equal for all experiments, so with Eq. (19) the critical standoff distances could be determined by Eq. (20).

Table 1 Experimental parameters

\begin{tabular}{|l|c|c|c|}
\hline \multicolumn{4}{|c|}{ Table 1 Experimental parameters } \\
\hline Nozzle type & A & B & C \\
\hline Spray angle, $\alpha$ & 660.216 & 660.366 & 660.446 \\
\hline Gauge pressure, $p$ & \multicolumn{3}{|c|}{$90^{\circ}$} \\
\hline Equivalent bore diameter, $D$ & $0,40 \mathrm{~mm}$ & $1,00 \mathrm{~mm}$ & $1,35 \mathrm{~mm}$ \\
\hline Volume flow rate at 2 bar & $0,111 / \mathrm{min}$ & $0,631 / \mathrm{min}$ & $1,251 / \mathrm{min}$ \\
{$[13], Q$} & 0,73 & 0,67 & 0,73 \\
\hline Flow coefficient, $k$ & $100 \mathrm{~mm}$ & $100 \mathrm{~mm}$ & $100 \mathrm{~mm}$ \\
& $150 \mathrm{~mm}$ & $150 \mathrm{~mm}$ & - \\
& $200 \mathrm{~mm}$ & $200 \mathrm{~mm}$ & $200 \mathrm{~mm}$ \\
& $250 \mathrm{~mm}$ & $250 \mathrm{~mm}$ & $250 \mathrm{~mm}$ \\
& $300 \mathrm{~mm}$ & $300 \mathrm{~mm}$ & $300 \mathrm{~mm}$ \\
Tested nozzle distances, $l$ & $340 \mathrm{~mm}$ & $340 \mathrm{~mm}$ & $340 \mathrm{~mm}$ \\
& $380 \mathrm{~mm}$ & $380 \mathrm{~mm}$ & $380 \mathrm{~mm}$ \\
& - & $470 \mathrm{~mm}$ & $470 \mathrm{~mm}$ \\
\hline \multirow{2}{*}{ Mean surface mass, $m_{0}$} & $9,4 \pm 0,6$ & $11,8 \pm 1,2$ & $8,6 \pm 1,7$ \\
& $m g / \mathrm{cm}^{2}$ & $\mathrm{mg} / \mathrm{cm}^{2}$ & $\mathrm{mg} / \mathrm{cm}^{2}$ \\
& & &
\end{tabular}

$l_{c i}=\frac{2,127}{2} \cdot\left(\frac{\lambda^{*} \psi}{S \cdot \tan \left(\frac{\alpha}{2}\right) \cdot C}\right)^{0,5} \cdot(p \rho)^{0,25}$.

$\cdot\left(\frac{k_{i}}{m_{0 i}}\right)^{0,5} \cdot D_{i}=$ const. $\cdot\left(\frac{k_{i}}{m_{0 i}}\right)^{0,5} \cdot D_{i}$.

This modified model for the cleaned width against nozzle distance was then adjusted to the experimental results only by the parameter $C$ and three constant factors in Eq. (20) respective to the three points in time.

\section{Results}

In Fig. 5 the results for $t=60 \mathrm{~s}$ are plotted as cleaned width $w_{\mathrm{c}}$ versus nozzle distance $l$. Furthermore the analytical curves predicted by the unmodified model according to Eq. (12) and (17) are shown. These curves are generated with equal values for $k$ and $\lambda$, so there is only a dependency of $l_{\text {c }}$ linear proportional to $D$. It is evident from Fig. 5 that there is a significant deviation between the unmodified model and the experimental values, particularly for the nozzle B series.

In Fig. 6 the cleaned width $w_{\mathrm{c}}$ is presented against the nozzle distance $l$ for the three different nozzles at discrete points in time. Additionally the analytical curves of the modified model are presented, by considering variations in $k$ and $m_{0}$ according to Eq. (12) and (20). With increasing nozzle diameter the maximum cleaned width also increases. For every nozzle there is an optimum and with enhanced nozzle diameter this optimum shifts to a longer nozzle distance. After the maximum of $w_{\mathrm{c}}$ the 
cleaning effect is decreasing with longer nozzle distance until no visible cleaning effect can be detected.

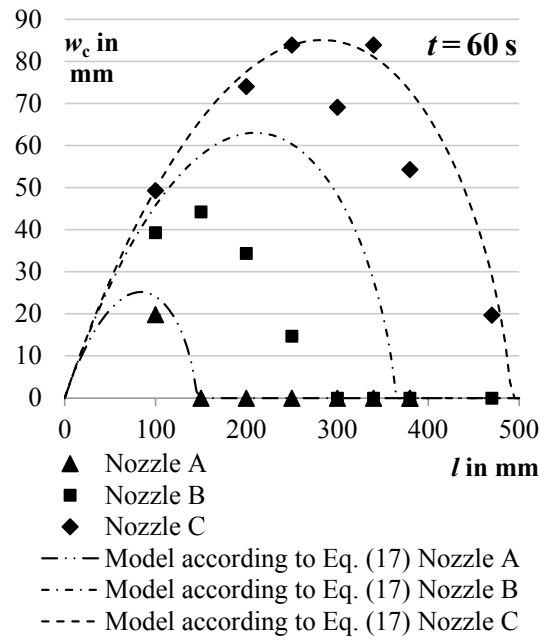

Figure 5 Cleaned width $w_{\mathrm{c}}$ vs. nozzle distance $l$ after $60 \mathrm{~s}$ - experimental results and analytical model with equal values for $k$ and $\lambda$ predicted by Eq. (17).

The measured data points and the analytical model agree fairly well for all points in time. Higher deviations occur for $t=30 \mathrm{~s}$ and for the nozzle $\mathrm{C}$ series.

Out of the adjusted constant values for the different points in time it is possible to determine the unknown ratio of $S$ to $\lambda^{*}$ by Eq. (20). These values are shown in Fig. 7 as a log-log-plot versus time.

\section{Discussion}

The shape of the analytical model is only related to the water distribution in $x$ direction, Eq. (12). The parameters $C$ and $l_{\mathrm{c}}$ only scale this curve. Due to this and the good agreement of the experimental data to the model loci it can be concluded that the assumption of Eq. (4) for the water distribution in $x$ direction is applicable to the used flat fan nozzles. A comparison of the model and cleaned width in $y$ direction was not possible due to the limited size of the test sheets and the high spray angle $\alpha$ of $90^{\circ}$. At greater distances the spray exceeded the test sheet and a cleaned width could not be determined.

The value for $C$ in these experiments is 0,33 which corresponds to a depth angle $\beta$ of $36^{\circ}$. This fairly high value is in agreement with observations from the experiments where a significant wider area of the test sheets was wetted but not cleaned.

The adaptations of the model to varying values for $k$ and surface mass $m_{0}$ lead to a significant improvement by comparing Figs. 5 and $6 \mathrm{~b}$. Thereby the influence of variations of $k$ is not as substantial as these by $m_{0}$. Additional deviations and particularly the higher scattering for the nozzle $\mathrm{C}$ series could be explained by the higher variations of the surface mass within each test series (see standard deviation of $m_{0}$ in Tab. 1). A detailed analysis showed that the upwards tending data points were test sheets with a lower surface mass and vice versa.

The decreasing value of the soil endurance limit $S$ with time in Fig. 7 , by assuming a constant $\lambda^{*}$ value, could be explained by soaking and swelling processes of the soil during cleaning. This leads to a weakening of the soil (decreasing $S$ ) with time and is in very good coexistence with previous experiences in the food industry.

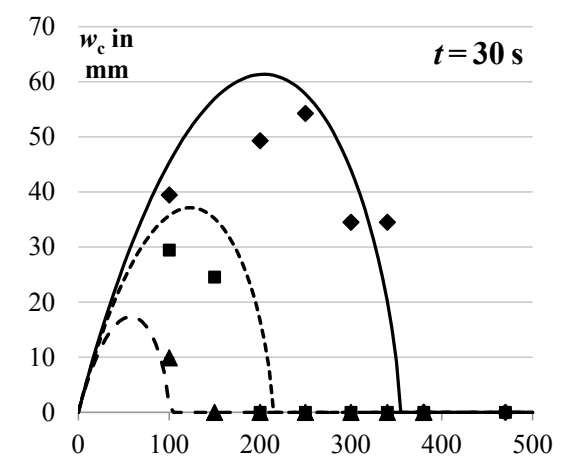

a)

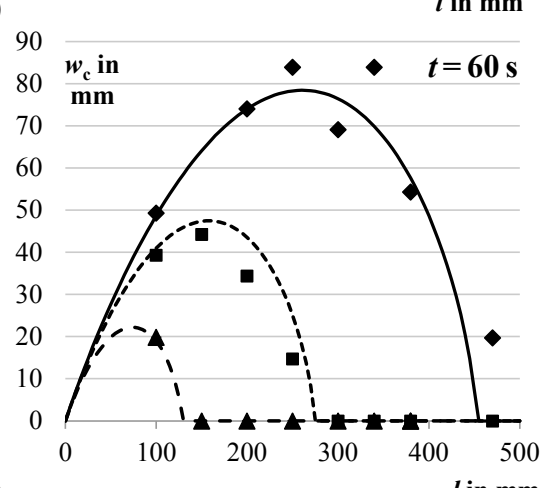

b)

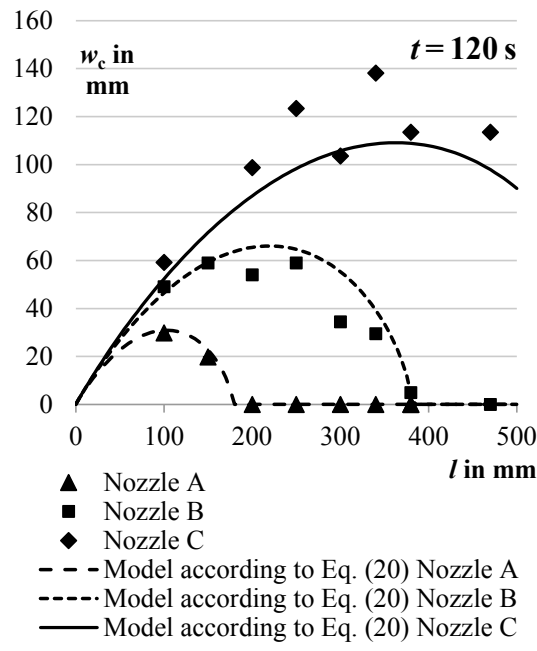

Figure 6 Cleaned width $w_{\mathrm{c}}$ vs. nozzle distance $l$ after a) $30 \mathrm{~s}$, b) $60 \mathrm{~s}$ and c) $120 \mathrm{~s}$ - experimental results and analytical model predicted by Eq. (20).

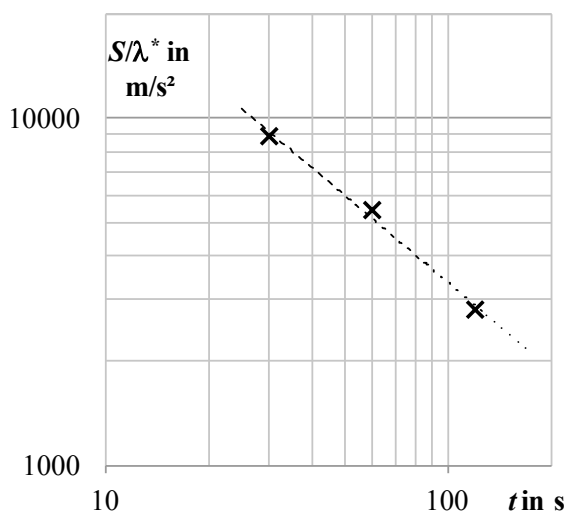

Figure 7 Dependency of soil endurance limit on time. Dashed line shows trend line obtained by linear regression. 


\section{Conclusion}

To choose efficient operating parameters and nozzles for a certain cleaning problem right from the design process a mathematical model would be of great interest. An existing model for high-pressure water jets was successfully transferred to a common low pressure water spray which is characteristic for cleaning in place (CIP) processes in the food industry. Additionally a relation was modelled which regards that the amount of water necessary to achieve a cleaning effect increases with thicker soil layer. The model relates a critical standoff distance with flow rate on discrete cleaning times, which is required because of the time dependency of soil endurance limit (Fig. 7). The models benefit is the ability to achieve optimal cleaning processes without numerous expensive cleaning investigations for every nozzle - soil combination. Once the soil endurance limit $S / \lambda^{*}$ was determined experimentally an optimal cleaning standoff distance can be calculated with nozzle data given by the manufacturer. We validated the model for a $90^{\circ}$ flat fan nozzle at 2 bar operating pressure. The agreement of analytic and experimental results could be improved by transferring the model to low pressure cleaning of a time independent food soil first and to add the influence of a time dependant soil endurance limit in a second step. Improvements of the mathematical model of low pressure cleaning and validation for wider ranged operating parameters will be part of ongoing research.

\section{Nomenclature}

C jet spreading coefficient, dimensionless

$D \quad$ nozzle diameter, $\mathrm{m}$

$j \quad$ mass flux, $\mathrm{kg} /\left(\mathrm{s} \cdot \mathrm{m}^{2}\right)$

$j_{0} \quad$ mass flux at the nozzle exit, $\mathrm{kg} /\left(\mathrm{s} \cdot \mathrm{m}^{2}\right)$

$j_{\mathrm{m}} \quad$ mass flux at the spray center line, $\mathrm{kg} /\left(\mathrm{s} \cdot \mathrm{m}^{2}\right)$

$k \quad$ flow coefficient, dimensionless

$l \quad$ nozzle distance, $\mathrm{m}$

$l_{\mathrm{c}} \quad$ critical nozzle distance, $\mathrm{m}$

$l_{\mathrm{c} \text { Leu }} \quad$ critical nozzle distance for round jets, $\mathrm{m}$

$m_{0} \quad$ mean surface mass coverage, $\mathrm{kg} / \mathrm{m}^{2}$

$p \quad$ gauge pressure, bar

$Q \quad$ volume flow rate, $\mathrm{m}^{3} / \mathrm{s}$

$r \quad$ radial coordinate, $\mathrm{m}$

$R \quad$ radial limit of the jet, $\mathrm{m}$

$\mathrm{S} \quad$ endurance limit, $\mathrm{N} / \mathrm{mm}^{2}$

$t \quad$ time, $\mathrm{s}$

$w_{\mathrm{c}} \quad$ cleaned width, $\mathrm{m}$

$x \quad$ cartesian coordinate, $\mathrm{m}$

$X \quad$ cartesian limit of the jet, $\mathrm{m}$

$y \quad$ cartesian coordinate, $\mathrm{m}$

$Y \quad$ cartesian limit of the jet, $m$

$\alpha \quad$ spray angle, angular degree

$\beta \quad$ depth angle, angular degree

$\gamma \quad$ dimensionless coordinate, dimensionless

$\lambda \quad$ stress coefficient, dimensionless

$\lambda^{*} \quad$ to surface mass adjusted stress coefficient, $\mathrm{kg} / \mathrm{m}^{2}$

$\xi \quad$ dimensionless coordinate, dimensionless

$\rho$ density, $\mathrm{kg} / \mathrm{m}^{3}$

$\psi \quad$ speed of sound, $\mathrm{m} / \mathrm{s}$

\section{Acknowledgement}

This research project is supported by funds of the European Union and the Free State of Saxony (SAB 080951793).

\section{References}

[1] Wildbrett, G. Reinigung und Desinfektion in der Lebensmittelindustrie. Behr`s Press, Hamburg, 2006.

[2] Mauermann, M. Methode zur Analyse von Reinigungsprozessen in nicht immergierten Systemen der Lebensmittelindustrie.// Dissertation, Technische Universität Dresden, 2012.

[3] Mulugeta, E. Niederdruckstrahlwäsche von Gemüse. // Dissertation, Universität Rostock, 2010.

[4] Scott, J. M.; Dunsmore, D. G.; Keegan, M. D. Spray nozzle performance in cleaning food equipment. // Transactions of the ASAE. 24, 2(1981), pp. 526-532. DOI: $10.13031 / 2013.34290$

[5] Wilson, D. I.; Atkinson, P.; Köhler, H.; Mauermann, M.; Stoye, H.; Suddaby, K.; Wang, T.; Davidson, J. F.; Majschak, J-P. Cleaning of soft-solid soil layers on vertical and horizontal surfaces by coherent impinging liquid jets. // Chemical Engineering Science. 109 (2014), pp. 183-196. DOI: 10.1016/j.ces.2014.01.034

[6] Chillman, A.; Ramulu, M.; Hashish, M. Waterjet and Water-Air Jet Surface Processing of a Titanium Alloy: A Parametric Evaluation. // Journal of Manufacturing Science and Engineering-Transactions of the ASME. 132, 1 (2010). pp. 526-532. DOI: 10.1115/1.4000837

[7] Krishnamurthy, A.; Li, W.; McMains, S. Simulation and Optimization of the Water-Jet Cleaning Process. // Amer Soc Mechanical Engineers, Proceedings of the $35^{\text {th }}$ Design Automation Conference / San Diego, 2009, pp. 891-898.

[8] Cao, L.; Liu, S.; Huang, Y.; Liu, Q.; Li, Z. Study of highpressure waterjet characteristics based on CFD simulation. // Industrial Design and Mechanical Power. 224, 1(2012). pp. 307-311. DOI: 10.4028/www.scientific.net/amm.224.307

[9] Gordon, P. W.; Chew, Y. M. J.; Wilson, D. I. Development of the scanning fluid dynamic gauge. // Proceedings of the 8th Int. Conf. On Heat Exchanger Fouling and Cleaning. / Budapest, 2009. http://www.heatexchanger-fouling.com/ papers/papers2009/67 Gordon F.pdf (06.01.2014).

[10] Leu, M. C.; Meng, P.; Geskin, E. S.; Tismeneskiy, L. Mathematical modeling and experimental verification of stationary waterjet cleaning process. // Journal of Manufacturing Science and Engineering-Transactions of the ASME. 120, 3 (1998), pp. 571-579. DOI: 10.1115/1.2830161

[11] Meng, P.; Geskin, E. S.; Leu, M. C.; Li, F. An analytical and experimental study of cleaning with moving waterjets. // Journal of Manufacturing Science and Engineering. 120, 3 (1998), pp. 580-589. DOI: 10.1115/1.2830162

[12] Köhler, H.; Mauermann, M.; Schöler, M.; Boye, A.; Calvimontes, A.; Majschak, J.-P. A novel quantitative evaluation method for cleaning processes on open surfaces independent of soil layer thickness. // Proceedings of the 9th Int. Conf. On Heat Exchanger Fouling and Cleaning. / Budapest, 2011. http://www.heatexchanger-fouling.com/ papers/papers2011/47 Koehler F.pdf (06.01.2014).

[13] Lechler GmbH; Flachstrahldüsen. // Data sheet 2014. http://www.lechler.de/is-bin/intershop.static/WFS/ LechlerDE-Shop-Site/LechlerDE-Shop/de_DE/ $\mathrm{PDF} / 05$ service support/industrie/katalog/deutsch/ Katalog_112/04_Flachstrahl_d_0613.pdf (03.12.2014). 


\section{Authors's addresses}

Köhler Hannes, Dipl.-Ing.

Technische Universität Dresden, Faculty of Mechanical

Engineering, Institute of Processing Machines and Mobile

Machines,

Bergstraße 120, 01062 Dresden, Germany

E-mail: hannes.koehler@tu-dresden.de

Stoye Hannes, Dipl.-Ing.

Technische Universität Dresden, Faculty of Mechanical

Engineering, Institute of Processing Machines and Mobile Machines,

Bergstraße 120, 01062 Dresden, Germany

Weyrauch Thomas, Dipl.-Ing

Fraunhofer IVV Dresden, Branch Lab for Processing Machinery and Packaging Technology AVV,

Heidelberger Straße 20, 01189 Dresden, Germany

Boye André, Dipl.-Ing.

Fraunhofer IVV Dresden, Branch Lab for Processing Machinery and Packaging Technology AVV,

Heidelberger Straße 20, 01189 Dresden, Germany

\section{Mauermann Marc, Dr.-Ing.}

Fraunhofer IVV Dresden, Branch Lab for Processing Machinery and Packaging Technology AVV,

Heidelberger Straße 20, 01189 Dresden, Germany

Majschak Jens-Peter, Prof. Dr.-Ing.

1) Technische Universität Dresden, Faculty of Mechanical Engineering, Institute of Processing Machines and Mobile

Machines,

Bergstraße 120, 01062 Dresden, Germany

2) Fraunhofer IVV Dresden, Branch Lab for Processing Machinery and Packaging Technology AVV,

Heidelberger Straße 20, 01189 Dresden, Germany 